\title{
Lorentz force-driven autonomous Janus swimmers
}

Gerardo Salinas, Kostiantyn Tieriekhov, Patrick Garrigue, Neso Sojic, Laurent Bouffier, Alexander Kuhn* Univ. Bordeaux, CNRS UMR 5255, Bordeaux INP, Site ENSCBP, F 33607 Pessac, France.

*Corresponding authors: kuhn@enscbp.fr

Table of Contents

Experimental procedures

Additional Data

Videos of the tracking particles and the macro- and micro-swimmers (AVI). 


\section{Experimental procedure}

$\mathrm{H}_{2} \mathrm{SO}_{4}$ (J. T. Baker, 95-97\%), Sodium dodecylbenzenesulfonate (Aldrich, technical grade), Mg foil (Goodfellow, $99.9 \%, 0.125$ mm of thickness), Pt foil (Goodfellow, 99.95\%, $0.1 \mathrm{~mm}$ of thickness), glassy carbon beads (Alfa Aesar, $d=200-400 \mu \mathrm{m}$ ), magnesium wire $\left(\varnothing=0.5 \mathrm{~mm}\right.$ ) and $\mathrm{H}_{2} \mathrm{PtCl}_{6} \mathrm{H}_{2} \mathrm{O}$ (Aldrich, 99.9\%) were used. All solutions were prepared with deionized water (MilliQ Direct-Q ${ }^{\circledR}$, resistivity $18.2 \mathrm{M} \Omega . \mathrm{cm}$ at $25^{\circ} \mathrm{C}$ ). Tracking experiments were performed in a plastic crystallizer with $5 \mathrm{~cm}$ diameter, whereas motion experiments were performed in a glass crystallizer with $20 \mathrm{~cm}$ diameter. A rectangular FeNdB magnet $\left(B \approx 200 \mathrm{mT}, A=98 \mathrm{~cm}^{2}\right)$ was placed below the crystallizer in order to produce a vertical magnetic field. Motion was monitored by using a CCD camera (CANON EOS 70D, Objective Canon Macro Lens 100 mm 1:2.8). Images and videos (AVI encoding) were processed with ImageJ software and finally converted to MP4 format. Each video can be presented as an accumulation of frames resulting in a stack projection. The tracking of the swimmers was performed with the plugin Manual tracking of the ImageJ software. Macro-Janus swimmers were built by attaching together $4 \mathrm{~mm}^{2}$ magnesium and platinum foils with silver glue. Then, the silver glue side was covered with blue and red nail polish, for magnesium and platinum, respectively. For the micro-Janus swimmers, the Mg wire was cut using a chirurgical scalpel. The precise length of the Mg rods was measured by using a macroscope (LEICA Z16 APO) and the average length is presented. The micro Mg/Pt swimmers were obtained following two straightforward steps: the required fraction of the wire was painted with nail varnish, then the particles were immersed in a $5 \mathrm{mM} \mathrm{H}_{2} \mathrm{PtCl}_{6}$ solution, under constant stirring for 5 minutes. After this time, the nail varnish was removed with 3 acetone washings. Distribution of the magnetic flux density above the surface of the FeNdB magnet was measured by using a GM08 Gaussmeter with a transversal probe (HIRST magnetic instruments Ltd). SEM experiments together with EDX mapping were carried out using a Vega3 Tescan $20.0 \mathrm{kV}$ microscope.

For the estimation of currents locally flowing between the $\mathrm{Mg}$ and Pt plates constituting the swimmer, two plates with the same size as in the swimmer configuration were connected with a wire via a multimeter and dipped in solutions with different acid concentrations. Currents ranging from $0.8 \mathrm{~mA}\left(10 \mathrm{mM} \mathrm{H}_{2} \mathrm{SO}_{4}\right)$ to $21 \mathrm{~mA}\left(100 \mathrm{mM} \mathrm{H}_{2} \mathrm{SO}_{4}\right)$ were measured. The Lorentz force was calculated using equation 1:

$F=I * L * B * \sin \alpha$

Where $L$ is the length of the macro-swimmer $\left(410^{-3} \mathrm{~m}\right), B$ the scalar value of the magnetic field at the center of the magnet $(0.2 \mathrm{~T})$, I the current $\left(510^{-3} \mathrm{~A}\right)$ and $\alpha$ the angle formed between the current and the magnetic field $\left(90^{\circ}\right)$. 
The Reynolds number $\left(R_{e}\right)$ was calculated based on equation 2:

$R_{e}=\frac{\rho * v * L}{\mu}$

Where $\rho$ is the density of the fluid $\left(1000 \mathrm{~kg} \mathrm{~m}^{-3}\right), v$ is the speed of the object $\left(110^{-2} \mathrm{~m} / \mathrm{s}\right), \mathrm{L}$ is the length of the object (4 $\left.10^{-3} \mathrm{~m}\right)$ and $\mu$ is the dynamic viscosity of the fluid $\left(110^{-3} \mathrm{~kg} \mathrm{~m}^{-1} \mathrm{~s}^{-1}\right)$. With these values a Reynold number of 40 was obtained. Consequently the drag force can be calculated using the Stoke's drag equation (eq. 3) considering two approximations: (i) the presence of a laminar flow, due to the rather low Reynolds number, and (ii) the macro-swimmer can be considered as an ellipsoid.

$F_{d}=6 * \pi * \mu * R * v$

with $\mu$ being the dynamic viscosity of the fluid $\left(110^{-3} \mathrm{~kg} \mathrm{~m}^{-1} \mathrm{~s}^{-1}\right), R$ the radius of the long side of the ellipsoid $\left(210^{-3} \mathrm{~m}\right)$ and $v$ is the speed of the object $\left(110^{-2} \mathrm{~m} / \mathrm{s}\right)$. With these values a drag force of $3.8 \times 10^{-7} \mathrm{~N}$ was calculated.

\section{Additional Data}

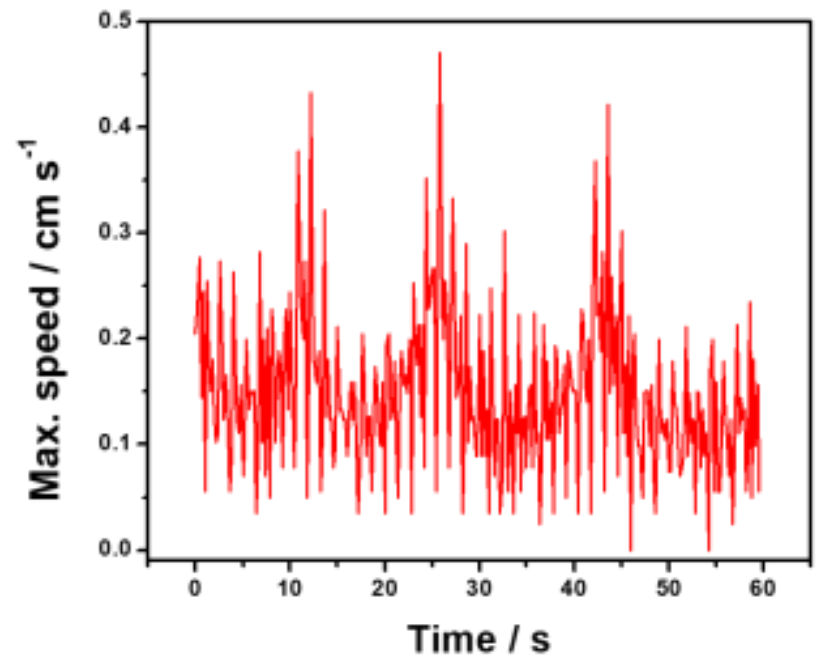

Figure S1. Speed profile versus time of a glassy carbon bead $(\varnothing=200-400 \mu \mathrm{m})$ moving on the air/water interface of a $0.05 \mathrm{mM} \mathrm{SDS}, 10 \mathrm{mM} \mathrm{H}_{2} \mathrm{SO}_{4}$ solution, above the metal plates, with the north pole of the magnet facing up. 

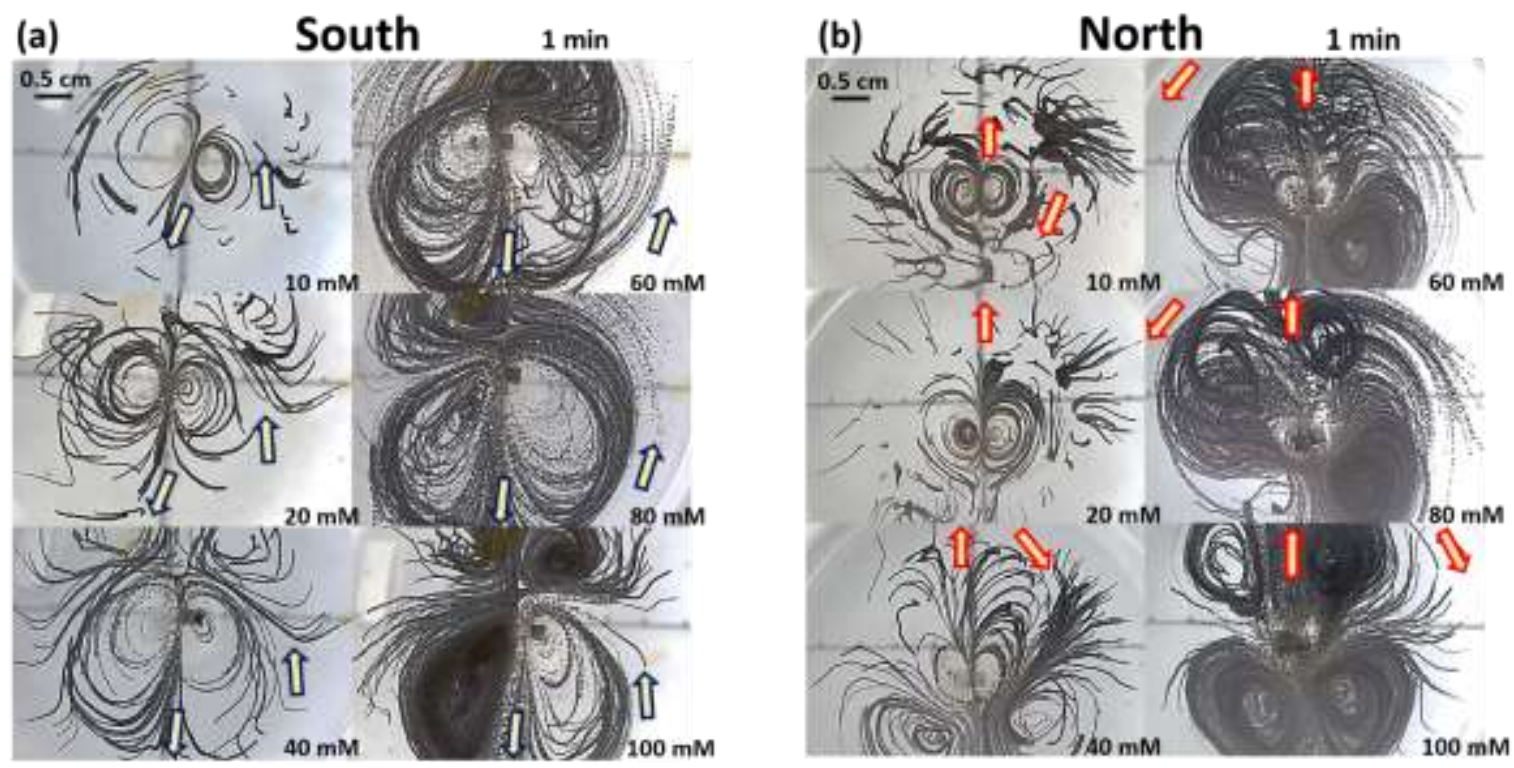

Figure S2. Trajectory of glassy carbon beads $(\varnothing=200-400 \mu \mathrm{m})$ moving at the air/water interface of a $0.05 \mathrm{mM}$ SDS solution, above the macro-Janus swimmer, as a function of the magnetic field orientation; (a) south pole up and (b) north pole up, with different $\mathrm{H}_{2} \mathrm{SO}_{4}$ concentrations (indicated in the figures). The global time of every experiment is $1 \mathrm{~min}$.

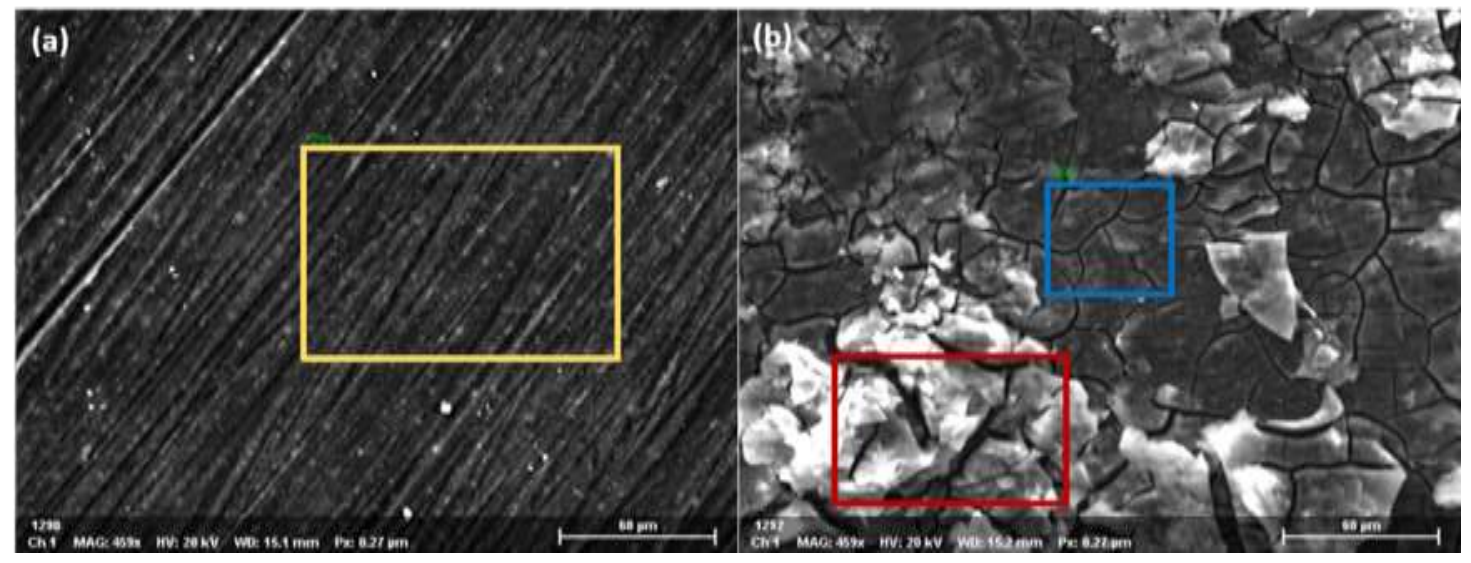

Figure S3. SEM images of the surface of (a) a pristine Mg electrode and (b) a Mg electrode after the ion flux visualization experiments. The squares indicate the selected areas for EDS analysis. 


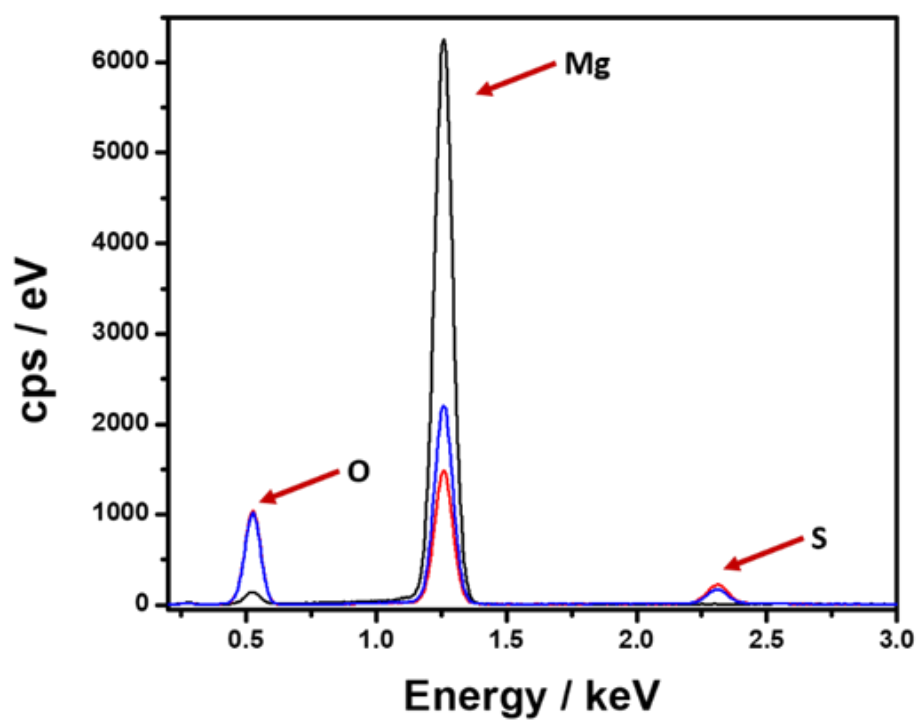

Figure S4. EDX signals around the emission peak of oxygen, magnesium and sulphur of a pristine Mg electrode (black line) and a Mg electrode after the ion flux visualization experiments (red and blue lines). The red and blue color code correlates with the areas selected in figure S3.

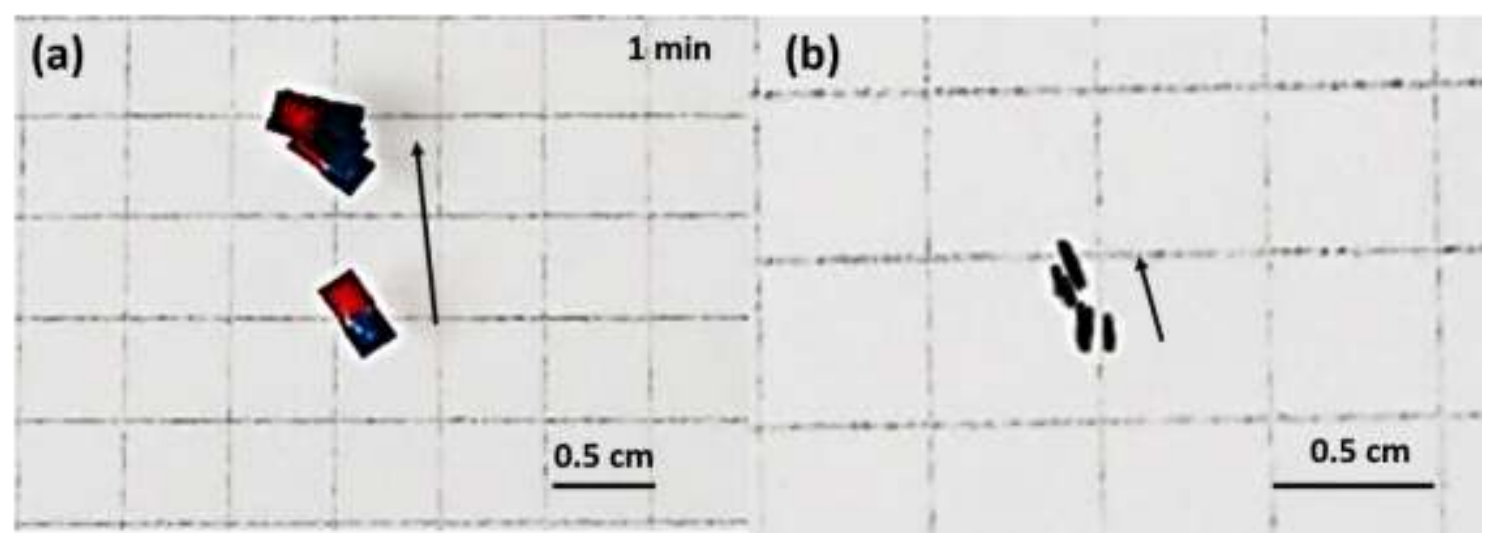

Figure S5. Accumulated time-laps images of a (a) macro- and (b) micro-Janus swimmer moving at the air/water interface of a $0.05 \mathrm{mM} \mathrm{SDS}, 40 \mathrm{mM} \mathrm{H}_{2} \mathrm{SO}_{4}$ solution, in the absence of magnetic field. The global time of every experiments is 1 minute (the magnesium plate is painted blue, the platinum part is red). 


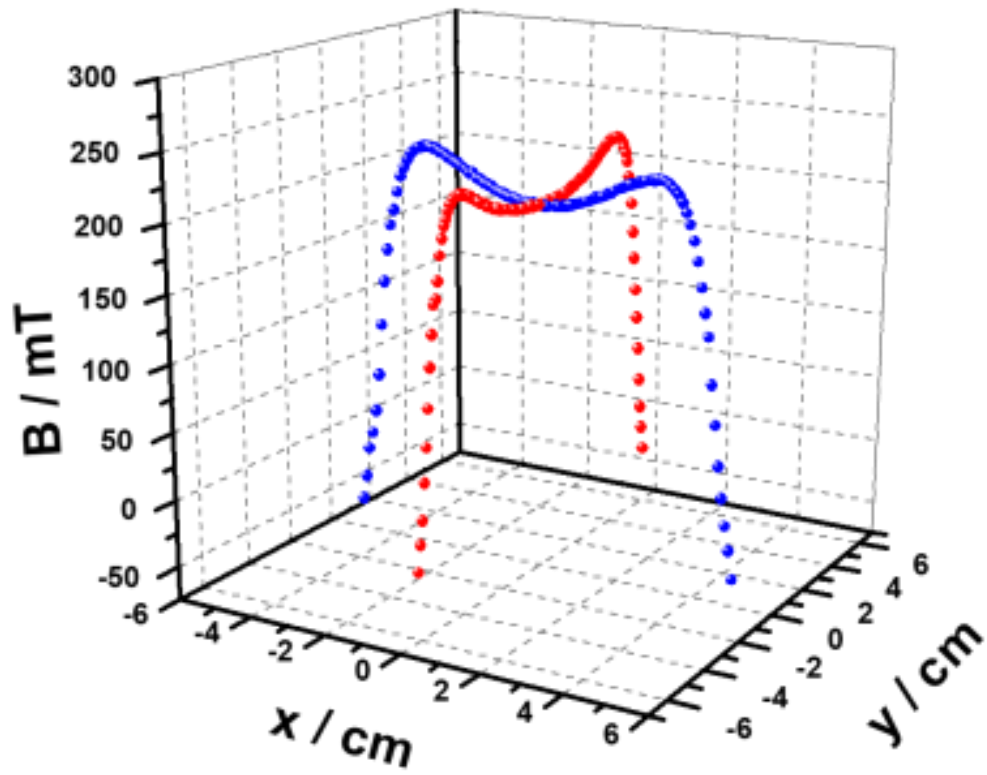

Figure S6. Plot of the distribution of the measured magnetic flux density above the surface of a FeNdB magnet $(B \approx 200$ $\left.\mathrm{mT}, A=98 \mathrm{~cm}^{2}\right)$. 
Video S1. Tracking particles $0.05 \mathrm{mM}$ SDS, $10 \mathrm{mM}$ sulfuric acid, x10, Magnesium on the right, Platinum on the left

Video S2. Tracking particles $0.05 \mathrm{mM}$ SDS, $20 \mathrm{mM}$ sulfuric acid, x10, Magnesium on the right, Platinum on the left

Video S3. Janus swimmers $0.05 \mathrm{mM}$ SDS, $40 \mathrm{mM}$ sulfuric acid, $\times 10$

Video S4. Janus macro-swimmers $0.05 \mathrm{mM}$ SDS, $40 \mathrm{mM}$ sulfuric acid.

Video S5. Janus macro-swimmers $0.05 \mathrm{mM}$ SDS, $40 \mathrm{mM}$ sulfuric acid.

Video S6. Janus micro-swimmers 0.05 mM SDS, 40 mM sulfuric acid, x10.

Video S7. Janus micro-swimmers 0.05 mM SDS, 40 mM sulfuric acid, x2. 